\title{
Optimization Model of the Ecological Water Replenishment Scheme for Boluo Lake National Nature Reserve Based on Interval Two-Stage Stochastic Programming
}

\author{
Jin Huang ${ }^{1}$, Lei Zhao ${ }^{2}$ and Shijun Sun ${ }^{2, *}$ \\ 1 Ecological Environmental Affairs Center of Hunan Province, Changsha 410000, China; sswzxhj@163.com \\ 2 School of Environment, Northeast Normal University, Changchun 130117, China; slzhaolei1981@126.com \\ * Correspondence: sunsj763@nenu.edu.cn; Tel.: +86-431-8916-5607
}

Citation: Huang, J.; Zhao, L.; Sun, S. Optimization Model of the Ecological Water Replenishment Scheme for Boluo Lake National Nature Reserve Based on Interval Two-Stage Stochastic Programming. Water 2021, 13, 1007. https://doi.org/10.3390/ w13081007

Academic Editor: Roko Andricevic

Received: 4 March 2021

Accepted: 30 March 2021

Published: 7 April 2021

Publisher's Note: MDPI stays neutral with regard to jurisdictional claims in published maps and institutional affiliations.

Copyright: (c) 2021 by the authors. Licensee MDPI, Basel, Switzerland. This article is an open access article distributed under the terms and conditions of the Creative Commons Attribution (CC BY) license (https:/ / creativecommons.org/licenses/by/ $4.0 /)$.

\begin{abstract}
In the present paper, an optimization model of the ecological water replenishment quantity of Boluo Lake wetland was constructed for ecological water replenishment in the Boluo Lake National Nature Reserve based on the interval two-stage stochastic programming (ITSP) method, which scientifically allocates the ecological water resources and enhances the utilization of flood resources in order to meet the minimum ecological water replenishment quantity requirement to meet the local economic and social water demand, to restore the wetland function of the reserve, and to improve the ecological environment. In addition, it considers the ecological service value of the reserve in order to achieve a shared increase in the ecological and economic benefits. The optimization model of the ecological water replenishment of Boluo Lake wetland considered the minimum ecological water replenishment as the objective function, while the water diversion capacity, water supply capacity, water diversion sequence, functional area, and ecological service value of the Lake bubble were utilized as constraints in order to restore the ecosystem function of the Boluo Lake National Nature Reserve. The results from the model revealed that the amount of ecological water replenishment was significantly reduced after optimization simulation, with the maximum reduction range in the ecological water replenishment being $-100.00 \%$ and $-74.58 \%$. In addition, the total amount of flood diversion was significantly increased, and the flood resources could be fully utilized. Moreover, the recovery effect on the lake and pond functional areas was significant and compared much better to that prior to the ecological water replenishment, which was up to $2300.00 \%$ and $1987.59 \%$. The ecological service value also increased significantly, and the rate of this increase was as high as $23.90 \%$ and $21.58 \%$. In the present study, an optimization model was constructed for the ecological water replenishment of the Boluo Lake wetland supplement project based on the interval two-stage stochastic programming method, which would achieve the entire scope of ecological and economic benefits of the ecological water replenishment project by realizing the ecological system reconstruction and providing a feasible and reliable plan to the decision-makers.
\end{abstract}

Keywords: interval two-stage stochastic programming (ITSP) method; Boluo Lake National Nature Reserve; wetland; ecological water replenishment; ecological service

\section{Introduction}

Wetlands are rich in biodiversity and are considered to be one of the most productive and economically valuable ecosystems in the world [1-3] because they provide the ecosystem products and services necessary for human activities, such as fish breeding, plant-carbon sequestration, biodiversity protection, cultural and entertainment services, etc. [4-8]. Despite their importance, over half of the wetland ecosystems in North America, Europe, Australia, and China have disappeared in the early 20th century due to the production activities conducted by humans $[9,10]$. Currently, there is a severe decline in the wetland ecosystems. The Boluo Lake National Nature Reserve, which is the only large natural wetland in the central part of the Jilin Province, belongs to the "Inland Wetland 
and Water Ecosystem" type of natural ecosystem. In recent years, this wetland ecosystem has been critically damaged due to the arid climate and over-exploitation by humans.

The amount of available ecological water is a key factor determining the function of the wetland ecosystem [11]. Therefore, the ecological supplement of the wetland is one of the most direct and effective methods for the restoration of a wetland area and improves the wetland ecosystem $[12,13]$. The main objectives of ecological recharge are to restore the hydrological and soil conditions of degraded wetlands, restore vegetation and faunal habitats, increase species composition, restore biodiversity and ultimately achieve the sustainable development of wetland ecosystems. The main objectives of ecological recharge are to restore hydrological and soil conditions in degraded wetlands, restore vegetation and fauna, increase species composition and restore biodiversity, and ultimately to achieve sustainable development of wetland ecosystems, which are beneficial to the local economy. Ecological water replenishment is applied widely in wetland restoration with good outcomes. Maleki et al. [14] employed a multicriteria-spatial decision support system (MC-SDSS) to design an ecological water replenishment program for the restoration of the Harmon wetland and to reduce the negative impact of drought on this wetland area. Xu et al. [15] constructed a random water allocation optimization model based on the watershed scale to conduct the ecological supplement of wetlands in the Xiaoqing River Basin and to restore the wetland activities in this region. Yang et al. [16] adopted an interval fuzzy double-sided chance-constrained stochastic programming method for designing the wetland ecological water replenishment project in the western region of the Jilin Province, which in addition to improving the ecological water supply, improved the local economic benefits as well. While the ecological water replenishment method is significantly effective in restoring the wetland ecosystem, the excessive allocation of ecological water replenishment may lead to water shortages in the reservoirs and rivers. Therefore, a scientific allocation of the ecological water replenishment is crucial in ecological water replenishment projects.

The interval two-stage stochastic programming method (ITSP) is a novel mathematical programming method that combines the interval programming method [17] with the twostage stochastic programming method (TSP) $[18,19]$, thereby reflecting the uncertainty of parameters in both interval and probability distribution forms. The ITSP method is applied widely to resolve the uncertainty problem and has achieved good results in various research fields. Maqsood et al. [20] employed the ITSP method in the uncertain conditions under the solid waste management system and formulated the waste flow model with the smallest system cost and the largest system feasibility. Meng et al. [21] employed the ITSP method to allocate water resources from the perspective of the pollution capacity of the Yinma River basin, and the wastewater carrying improvement project was adopted, which promoted the improvement in the quality of the water environment to a certain extent. Qiu et al. [22] constructed an optimal allocation model of flood resources based on the ITSP method and incorporated the corresponding flood resource effectiveness under the different discharge scenarios of the Nenjiang River into the total water resources, which improved the flood utilization rate.

In summary, the present study involved the construction of an optimization model based on the ITSP method for the ecological water replenishment of the Baluo Lake wetland supplement project. By utilizing the minimum ecological water replenishment amount of the Boluo Lake National Nature Reserve as the objective function, the optimal allocation of the ecological water replenishment quantity of each lake bubble was performed to ensure the complete utilization of the flood resources, to increase the amount of flood resources, and to effectively restore the lake bubble and the wetland area in reserve. Meanwhile, the ecological service value of the protected area was considered in order to realize the improvement in both ecological and economic benefits. 


\section{Study Area}

The Boluo Lake National Nature Reserve is located in the northwest region of Nong'an County, Changchun City, Jilin Province. Figure 1 is the map of the Boluo Lake National Nature Reserve. It spans an area of 24,915 hectares and is the only large natural wetland in the central region of the Jilin Province [23]. It is located at the western edge of the depression in the southeast region of the Songliao Plain, with the terrain higher in the southeast and lower in the northwest. Boluo Lake is an inland closed-flow alkaline freshwater lake [24,25]. The Boluo Lake wetland has remained dry for a long time, the rivers in the reserve have been cut-off, and the groundwater level has dropped, which has resulted in a decrease in the lake water, the phenomenon of drying up, a serious reduction in the wetland area, and aggravation of soil erosion. Owing to the unique terrain of this region, the circulation in the water resources is relatively difficult, while soil desertification and land salinization are aggravated, which has caused a serious impact on the local ecosystem security and gradual degradation of the wetland ecosystem function.

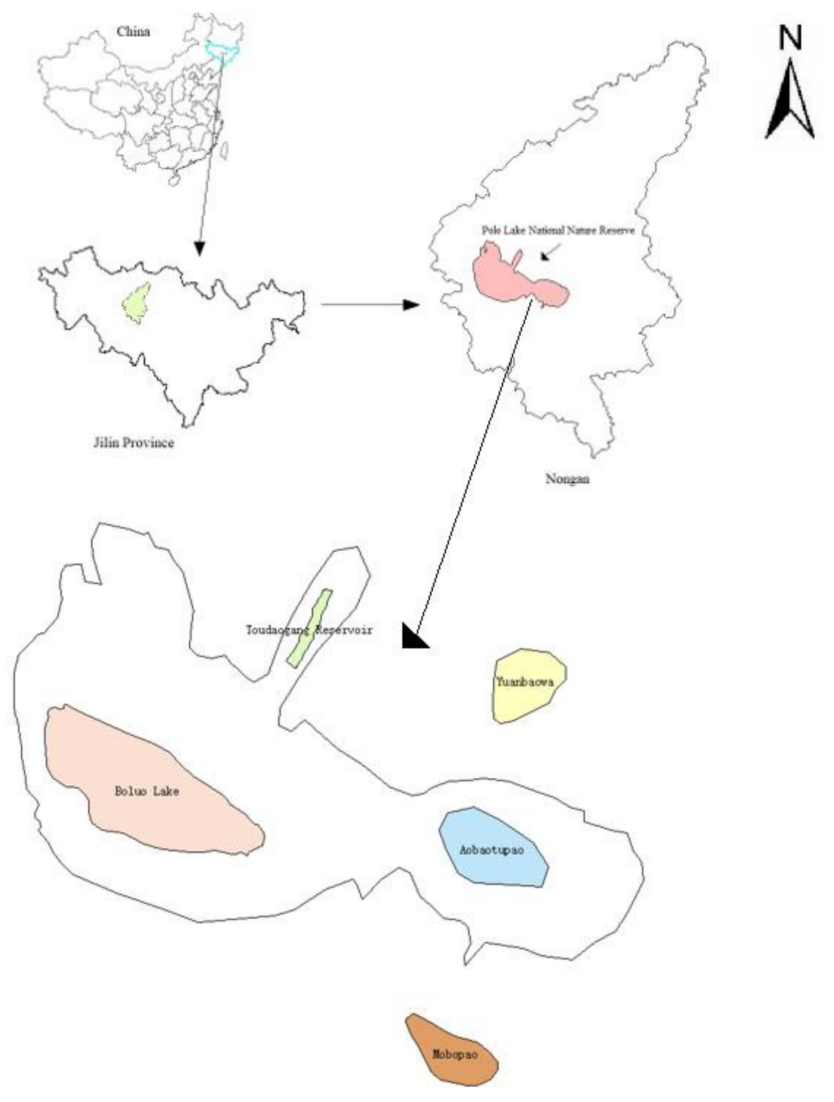

Figure 1. The geographical locations of the study area.

\section{Model Formulation}

3.1. Construction of the Ecological Water Replenishment Optimization Model for the Boluo Lake Wetland Based on the ITSP Method

The objective of the present study was to realize the restoration of wetland function and the reconstruction of the wetland ecosystem in the Boluo Lake wetland water replenishment project using minimum ecological water supply through the scientific allocation of the ecological water resources. Therefore, in the present study, the minimum ecological water replenishment was considered to be the objective, while the water diversion capacity, water replenishment quantity of the lake bubbles, and water supply capacity were utilized as constraints. Finally, an ecological water replenishment optimization model, based on 
the ITSP method, was constructed for the Boluo Lake wetland water replenishment project. The model may be expressed as follows:

$$
\min \mathrm{f}^{ \pm}=\sum_{\mathrm{i}=1}^{5} \mathrm{EAT}_{\mathrm{i}}^{ \pm} \times \mathrm{QT}_{\mathrm{i}}^{ \pm}-\sum_{\mathrm{i}=1}^{5} \sum_{\mathrm{j}=1}^{4} \sum_{\mathrm{h}=1}^{3} \mathrm{p}_{\mathrm{h}} \times \mathrm{DEA}_{\mathrm{ijh}}^{ \pm} \times \mathrm{QLT}_{\mathrm{ih}}^{ \pm}
$$

where $f$ represents the total quantity of ecological water replenishment in the Boluo Lake National Nature Reserve; $\mathrm{i}=1$ to 5 represent the Toudaogang Reservoir, Boluo Lake, Mobopao, Yuanbaowapao, and Aobaotupao, respectively, in the Nature Reserve; $j=1$ to 4 represent the four different ecosystem types, namely, fish ponds, crab ponds, reed wetlands, and marsh wetlands, respectively; $h=1$ to 3 represent the flood amount levels in the low flow years, normal flow years, and high flow years, respectively; $\mathrm{p}_{\mathrm{h}}$ denotes the scenario probability; $\mathrm{EAT}_{i}^{ \pm}$represents the area of water replenishment recommended by the project $\left(\mathrm{hm}^{2}\right)$; $\mathrm{QT}_{\mathrm{i}}^{ \pm}$represents the total water replenishment amount for the lake and pond $\left(\mathrm{t} / \mathrm{hm}^{2}\right)$; $\mathrm{DEA}_{\mathrm{ijh}}^{ \pm}$represents the area adjustment amount for the lake and pond $\mathrm{i}$ in the ecosystem $\mathrm{j}$ under scenario $\mathrm{h}\left(\mathrm{hm}^{2}\right)$; and $\mathrm{QLT}_{\mathrm{ih}}^{ \pm}$represents the total water transport loss for the lake and pond $i$ under scenario $h$.

(1) Constraints for water diversion and supplementation amount [23]:

$$
\begin{aligned}
& \left(\mathrm{AP}_{\mathrm{i}}^{ \pm}-\mathrm{DAP}_{\mathrm{ih}}^{ \pm}\right) \times \mathrm{QWR}_{\mathrm{i}}^{ \pm} \leq \mathrm{QAP}_{\mathrm{ih}}^{ \pm}, \forall \mathrm{i}, \mathrm{h} \\
& \sum_{\mathrm{j}=3}^{4}\left(\mathrm{EA}_{\mathrm{ij}}^{ \pm}-\mathrm{DEA}_{\mathrm{ijh}}^{ \pm}\right) \times \mathrm{QP}_{\mathrm{ij}}^{ \pm} \leq \mathrm{QAW}_{\mathrm{ih}}^{ \pm}, \forall \mathrm{i}, \mathrm{h}
\end{aligned}
$$

(2) Constraints for the water supply capacity [26]:

$$
\begin{gathered}
\mathrm{QAI}_{\mathrm{ih}}^{ \pm} \leq \mathrm{QI}_{\mathrm{i}}^{ \pm}, \forall \mathrm{i}, \mathrm{h} \\
\mathrm{QAN}_{\mathrm{ih}}^{ \pm} \leq \mathrm{QN}_{\mathrm{i}}^{ \pm}, \forall \mathrm{i}, \mathrm{h}
\end{gathered}
$$

where $\mathrm{QAI}_{\mathrm{ih}}^{ \pm}$represents the local water amount in the lake and pond $\mathrm{i}$ under scenario $\mathrm{h}\left(\mathrm{m}^{3}\right) ; \mathrm{QI}_{\mathrm{i}}^{ \pm}$represents the local water in the lake and pond $\left(\mathrm{m}^{3}\right) ; \mathrm{QAN}_{\mathrm{ih}}^{ \pm}$represents the normal supplement of the lake and pond i under scenario $\mathrm{h}\left(\mathrm{m}^{3}\right)$; and $\mathrm{QN}_{\mathrm{i}}^{ \pm}$ represents the normal supplement of the lake and pond $\left(\mathrm{m}^{3}\right)$.

(3) Constraints for the functional area [23]:

$$
\begin{gathered}
\mathrm{AP}_{\mathrm{i}}^{ \pm}-\mathrm{DAP}_{\mathrm{ih}}^{ \pm} \geq 0, \forall \mathrm{i}, \mathrm{h} \\
\mathrm{EA}_{\mathrm{ij}}^{ \pm}-\mathrm{DEA}_{\mathrm{ijh}}^{ \pm} \geq 0, \forall \mathrm{i}, \mathrm{h} \\
\sum_{\mathrm{j}=1}^{2} \mathrm{EA}_{\mathrm{ij}}^{ \pm}-\mathrm{DEA}_{\mathrm{ijh}}^{ \pm} \leq \mathrm{AP}_{\mathrm{i}}^{ \pm}-\mathrm{DAP}_{\mathrm{ih}}^{ \pm}, \forall \mathrm{i}, \mathrm{h} \\
\left(\mathrm{AP}_{\mathrm{i}}^{ \pm}-\mathrm{DAP}_{\mathrm{ih}}^{ \pm}\right)+\sum_{\mathrm{j}=3}^{4}\left(\mathrm{EA}_{\mathrm{ij}}^{ \pm}-\mathrm{DEA}_{\mathrm{ijh}}^{ \pm}\right) \leq \mathrm{PLA}_{\mathrm{i}}^{ \pm}, \forall \mathrm{i}, \mathrm{h}
\end{gathered}
$$

where $\mathrm{PLA}_{\mathrm{i}}^{ \pm}$represents the upper limit of the area of the lake and pond $\mathrm{i}\left(\mathrm{hm}^{2}\right)$.

(4) Constraints for the diversion and supplement of the water amount [24]:

$$
\sum_{\mathrm{i}=1}^{5}\left[\sum_{\mathrm{j}=1}^{4}\left(\mathrm{EA}_{\mathrm{ij}}^{ \pm}-\mathrm{DEA}_{\mathrm{ijh}}^{ \pm}\right) \times \mathrm{QP}_{\mathrm{ij}}^{ \pm}-\mathrm{QAI}_{\mathrm{ih}}^{ \pm}-\mathrm{QAN}_{\mathrm{ih}}^{ \pm}\right] \leq \mathrm{QTF}_{\mathrm{ih}}^{ \pm}, \forall \mathrm{h}
$$

where QTF $F_{\mathrm{ih}}^{ \pm}$represents the amount of flood resources in the lake and pond $\mathrm{i}$ under scenario $\mathrm{h}\left(\mathrm{m}^{3}\right)$.

(5) Constraints for water diversion and the supplementation order [24]: 


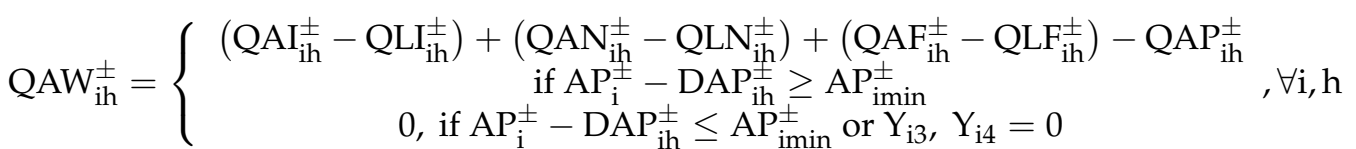

$$
\begin{aligned}
& \left(\mathrm{EA}_{\mathrm{i} 4}^{ \pm}-\mathrm{DEA}_{\mathrm{i} 4 \mathrm{~h}}^{ \pm}\right) \times \mathrm{QP}_{\mathrm{i} 4}^{ \pm}=\left\{\begin{array}{c}
\mathrm{QAW}_{\mathrm{ih}}^{ \pm}-\left(\mathrm{EA}_{\mathrm{i} 3}^{ \pm}-\mathrm{DEA}_{\mathrm{i} 3 \mathrm{~h}}^{ \pm}\right) \times \mathrm{QP}_{\mathrm{i} 3}^{ \pm} \\
\text {if } \mathrm{EA}_{\mathrm{i} 3}^{ \pm}-\mathrm{DEA}_{\mathrm{i} 3 \mathrm{~h}}^{ \pm} \geq \mathrm{EA}_{\mathrm{mini}}^{ \pm} \text {and } \mathrm{Y}_{\mathrm{i} 4}^{ \pm}=1 \\
0, \text { if } \mathrm{EA}_{\mathrm{i} 3}^{ \pm}-\mathrm{DEA}_{\mathrm{i} 3 \mathrm{~h}}^{ \pm} \leq \mathrm{EA}_{\mathrm{mini} 3}^{ \pm} \text {and } \mathrm{Y}_{\mathrm{i} 4}=0
\end{array}, \forall \mathrm{i}, \mathrm{h}\right.
\end{aligned}
$$

where $\mathrm{QLI}_{\mathrm{ih}}^{ \pm}$represents the loss of local water transport for the lake and pond $\mathrm{i}$ under scenario $\mathrm{h}\left(\mathrm{m}^{3}\right) ; \mathrm{QLN}_{\mathrm{ih}}^{ \pm}$represents the loss of water transport for the normal supplement of the lake and pond i under scenario $\mathrm{h}\left(\mathrm{m}^{3}\right)$; $\mathrm{QLF}$ ih represents the loss of water transport for the flood diversion and supplement of the lake and pond $i$ under scenario $\mathrm{h}\left(\mathrm{m}^{3}\right) ; \mathrm{Y}_{\mathrm{i} 3}$ denotes the presence or absence of the reed wetland in the lake and pond $\mathrm{i} ; \mathrm{Y}_{\mathrm{i} 4}$ denotes the presence or absence of marsh wetland in the lake and pond $\mathrm{i} ; \mathrm{Y}=0$ denotes that the type of wetland is present; and $\mathrm{Y}=1$ denotes that there is no such type of wetland.

(6) Constraints for the ecological value:

$$
\begin{gathered}
\mathrm{TEBE}_{\mathrm{kh}}^{ \pm}=\sum_{\mathrm{i}=1}^{5} \sum_{\mathrm{j}=1}^{4} \mathrm{EBW}_{\mathrm{jk}}^{ \pm} \times\left(\mathrm{EA}_{\mathrm{ij}}^{ \pm}-\mathrm{DEA}_{\mathrm{ijh}}^{ \pm}\right) \\
\mathrm{TEBE}_{\mathrm{kh}}^{ \pm} \geq \mathrm{TEB}_{\mathrm{k}}^{ \pm}
\end{gathered}
$$

where $\mathrm{k}$ is the ecosystem service function of the reserve; $\mathrm{TEBE}_{\mathrm{kh}}^{ \pm}$represents the total ecological value of the indicator system under scenario $\mathrm{h}\left(10^{4} \mathrm{CNY}\right) ; \mathrm{EBW}_{\mathrm{jk}}^{ \pm}$represents the ecological value compensation of the ecosystem $\mathrm{j}\left(10^{4} \mathrm{CNY}\right)$; and $\mathrm{EBW}_{\mathrm{jk}}^{ \pm}$represents the total ecological value of the index system of the project scheme $\left(10^{4} \mathrm{CNY}\right)$.

The non-negative constraint:

$$
\mathrm{QAI}_{\mathrm{ih}}^{ \pm}, \mathrm{QAN}_{\mathrm{ih}}^{ \pm}, \mathrm{QAF}_{\mathrm{ih}}^{ \pm}, \mathrm{QAW}_{\mathrm{ih}}^{ \pm}, \mathrm{QAP}_{\mathrm{ih}}^{ \pm} \geq 0
$$

In the optimization scheme, the water replenishment quantity of each lake and pond is non-negative.

\subsection{Model Parameters}

The present work considered the Toudaogang Reservoir, Boluo Lake, Mobopao, Yuanbaowapao, and Aobaotupao in the Boluo Lake Wetland National Nature Reserve as the study areas. Each of these five study areas were divided into four types, namely fish pond, crab pond, reed wetland, and marsh wetland. Three scenarios, namely, low flow years, normal flow years, and high flow years, were set for the analysis. The scenario probability for each of these scenarios was $0.55,0.3$, and 0.15 , respectively. The original data used in the present paper are from the interconnected river systems in the western region of the Jilin Province that had to be implemented.

Lingo18.0 software was employed to solve the optimization model based on the ITSP method for the ecological water replenishment of the Boluo Lake wetland supplement project. The model solution was obtained in two steps. First, the upper bound sub-model was established and solved. The initial area of the different land types in each study area in the first stage and the lower limit of the reduced area of the different land types in each study area in the second stage were calculated. Next, the initial area calculated in the first step was utilized as the constraint of the lower boundary sub-model to further solve the lower boundary sub-model. 


\section{Results, Analysis and Discussion}

4.1. Analysis of the Ecological Water Replenishment Variation in the Boluo Lake Wetland Water Replenishment Project Based on the ITSP Method

4.1.1. Ecological Water Replenishment Configuration Scheme for the Boluo Lake Wetland Water Replenishment Project Based on the ITSP Method

The objective of the present study was to alleviate the water shortage in the lake wetlands in the Boluo Lake Wetland National Nature Reserve through the complete utilization of the water resources via ecological replenishment to achieve the restoration of the lake wetland area in the reserve, as well as the reconstruction of the ecosystem, while ensuring the ecological service value of the reserve. The ecological replenishment quantity for each lake in the Boluo Lake Wetland National Nature Reserve is presented in Table 1. Additionally, Figure 2 shows a comparison of the recommended ecological water replenishment project and the ITSP model optimization scheme for each lake in the Boluo Lake Wetland National Nature Reserve.

Table 1. Ecological water replenishment for each lake bubble in the Boluo Lake Wetland National Nature Reserve.

\begin{tabular}{cccc}
\hline \multirow{2}{*}{ Name of Lake Bubble } & \multicolumn{3}{c}{ Total Water Replenishment $\left.\mathbf{( 1 0}^{\mathbf{4}} \mathbf{~ m}^{\mathbf{3}}\right)$} \\
\cline { 2 - 4 } & Original Scheme & ITSP Model & Range of Variation \\
\hline Toudaogang Reservoir & 651.46 & $(562.40,692.94)$ & $(-13.67 \%, 6.37 \%)$ \\
Boluo Lake & 5289.64 & $(697.50,6476.21)$ & $(-86.81 \%, 22.43 \%)$ \\
Mobopao & 768.72 & $(41.60,698.60)$ & $(-94.59 \%,-9.12 \%)$ \\
Yuanbaowapao & 546.50 & $(0.00,138.90)$ & $(-100.00 \%,-74.58 \%)$ \\
Aobaotupao & 1211.64 & $(234.40,1798.29)$ & $(-80.65 \%, 48.42 \%)$ \\
\hline
\end{tabular}

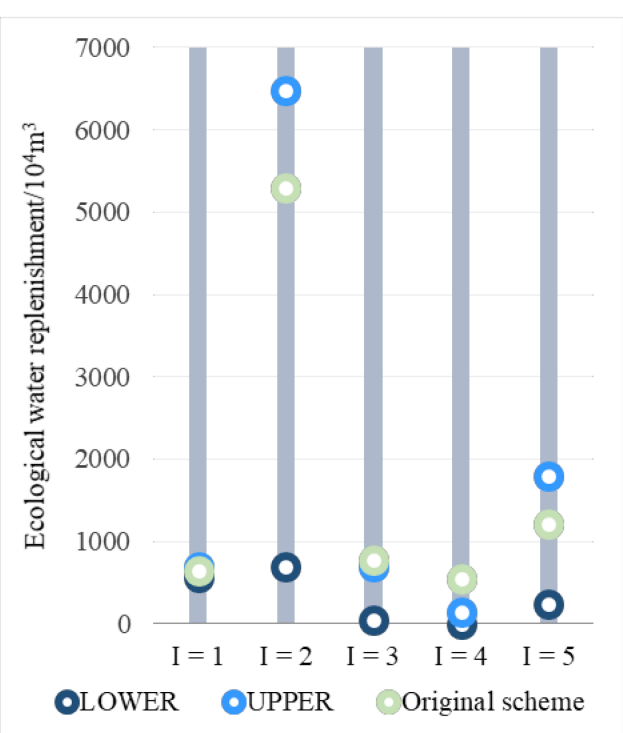

Figure 2. Comparison between the recommended scheme for the project and the ITSP-based model optimization scheme for the ecological water replenishment project of each lake in the Boluo Lake Wetland National Nature Reserve. ( $I=1$ to 5 represent the Toudaogang Reservoir, Boluo Lake, Mobopao, Yuanbaowapao, and Aobaotupao, respectively).

After the optimization, the total ecological water replenishment of the Toudaogang Reservoir was altered to $-13.67 \%$ and $6.37 \%$, with a decrease in the lower limit of the total ecological water replenishment in the area and an increase in the upper limit compared to the recommended scheme for the project. Meanwhile, the total ecological water replenishment for the Boluo Lake was altered to $-86.81 \%$ and $22.43 \%$, with a significant decrease in the lower limit of total ecological water replenishment and an increase in the upper limit of the area compared to the recommended scheme for the project. Moreover, 
the total ecological water replenishment for Mobopao was altered to $-94.59 \%$ and $-9.12 \%$, with both upper and lower limits of the total ecological water replenishment in the area reduced, as compared to the recommended scheme for the project and a significant reduction in the lower limit. Furthermore, the total ecological water replenishment for the Yuanbaowapao was altered to $-100.00 \%$ and $-74.58 \%$, with both upper and lower limits of the total ecological water replenishment in the area significantly reduced compared to the recommended scheme for the project. In addition, the total ecological water replenishment for the Aobaotupao was altered to $-80.65 \%$ and $48.42 \%$, with a significant decrease in the lower limit of the total ecological water replenishment in the area and a significant increase in the upper limit compared to the recommended scheme for the project. A comprehensive analysis of the changes in the ecological water replenishment in the study area revealed that the changes in the ecological water replenishment varied from one lake bubble to another, although the lower limit of the ecological water replenishment was significantly low in all five bubbles, while the upper and lower limits of the ecological water replenishment for Mobopao and Yuanbaowapao were relatively lower. Overall, the total ecological water replenishment in the Boluo Lake Wetland National Nature Reserve was reduced, and the simulation results for this optimization scheme are presented in the form of intervals in order to enable the decision-makers to allocate and adjust the ecological water replenishment of each lake bubble according to the actual situation while undertaking decisions.

4.1.2. Variation in the Flood Diversion Volume of the Water Replenishment Project for the Boluo Lake Wetland Based on the ITSP Method

In order to ensure safety, flood waters could be diverted and stored in the form of usable inland water to be used as a resource as required [27,28]. In the ecological water replenishment of wetlands, increasing the amount of flood resources utilized is conducive to reducing the amount of water replenishment required in the other methods of water replenishment, thereby achieving the optimal utilization of the water resources of ecological water replenishment [29]. The values of the flood diversion volume from each lake bubble under different scenarios are presented in Table 2.

Table 2. Flood diversion volumes for each of the lake bubbles in the Boluo Lake under different scenarios.

\begin{tabular}{|c|c|c|c|c|}
\hline \multirow{3}{*}{ Name of Lake Bubble } & \multicolumn{4}{|c|}{ Flood Diversion Volume $\left(10^{4} \mathrm{~m}^{3}\right)$} \\
\hline & \multirow{2}{*}{$\begin{array}{l}\text { The Recommended } \\
\text { Scheme for Project }\end{array}$} & \multicolumn{3}{|c|}{ ITSP Model } \\
\hline & & $\mathbf{H}=\mathbf{1}$ & $\mathbf{H}=\mathbf{2}$ & $\mathbf{H}=\mathbf{3}$ \\
\hline Toudaogang Reservoir & 0.00 & $(0.00,335.63)$ & $(0.00,335.63)$ & $(0.00,335.63)$ \\
\hline Boluo Lake & 621.00 & $(0.00,0.00)$ & $(0.00,0.00)$ & $(0.00,0.00)$ \\
\hline Mobopao & 295.00 & $(0.00,431.10)$ & $(0.00,478.80)$ & $(0.00,12.60)$ \\
\hline Yuanbaowapao & 2.00 & $(0.00,289.80)$ & $(0.00,289.80)$ & $(0.00,56.70)$ \\
\hline Aobaotupao & 14.00 & $(0.00,910.70)$ & $(0.00,910.70)$ & $(0.00,910.70)$ \\
\hline Total & 932.00 & $(0.00,1967.23)$ & $(0.00,2014.93)$ & $(0.00,1315.63)$ \\
\hline
\end{tabular}

In the recommended scheme for the project, the Toudaogang Reservoir region did not utilize the flood resources, while in the ITSP optimization scheme, the Boluo Lake region did not utilize the flood resources. This was a consequence of optimizing the flood diversion volume for each lake bubble in the Boluo Lake Wetland National Nature Reserve, considering the water diversion sequence and water supply capacity as constraints. In Mobopao, the flood diversion volumes in the three scenarios were in the range of $(0.00$, $431.10),(0.00,478.80)$, and $(0.00,12.60)$, respectively, while in the Yuanbaowapao, the flood diversion volume ranges in the three scenarios were $(0.00,289.80),(0.00,289.80)$, and $(0.00$, 56.70), respectively. It could be observed that the flood diversion volumes in each of the lake bubbles were varied in the different scenarios, which was mainly because of the high flow years, the water resources being plentiful, and the ecological water replenishment being accordingly adjusted downwards. Since floods are usually diverted by storing the 
floodwater in reservoirs during the flood season, they are converted into usable water resources [30]. Therefore, it is possible to control the allocation of the flood resources in ecological water replenishment and rationalize it according to the different scenarios. While the flood diversion volume ranges vary from region to region, the upper limit of the total flood diversions remained substantially higher compared to that in the recommended scheme for the project, due to which the results of the optimized scheme were presented in the form of intervals, providing a wider scope for decision-making.

\subsection{Analysis of the Ecological Water Replenishment Variation in the Boluo Lake Wetland Water Replenishment Project Based on the ITSP Method}

Ecological water replenishment is one of the most direct and effective ways to reconstruct the wetland ecosystem and to restore its functions [31,32], thereby resolving the issues of wetland area reduction and effectively restoring the wetland areas. The initial areas of the different functional areas within each lake bubble in the Boluo Lake Wetland National Nature Reserve, the areas of the recommended scheme for the project, and the areas of each ecosystem type after optimization using the ITSP method are presented in Table 3 , and the changes in the areas of each ecosystem type after optimization using the ITSP method compared to those in the areas of the original scheme are presented in Figure 3. As presented in Table 3, in the Toudaogang Reservoir, the largest area after optimization was the fish pond restoration area, which reached a value of $(0.72,1.04) \times 10^{4} \mathrm{hm}^{2}$, accounting for an increase of $(2300.00 \%, 1987.59 \%)$, as compared to the initial area. While the lower limits of the reed wetland area and the marsh wetland area were lower than those of the corresponding initial areas, the upper limits were increased by $700.00 \%$ and $716.00 \%$, respectively. In the Boluo Lake, the largest after the optimization was the area of fish ponds, with a value of $(2.94,8.00) \times 10^{4} \mathrm{hm}^{2}$, which was an increase of $(326.76 \%$, $515.35 \%$ ) compared to the initial area. In the Boluo Lake region, except for the crab ponds, the other three functional regions greatly exhibited increased upper and lower limits of their respective areas. In Mobopao, except for the crab pond area that remained unchanged, the other three functional regions exhibited decreased lower limits of their respective areas compared to the initial area, while the upper limits of their areas increased significantly by $449.72 \%, 700.00 \%$, and $700.00 \%$, respectively. In Yuanbaowapao, no change occurred in the lower limits of the fish pond area and crab pond area after the optimization. The lower limits of two areas, the reed wetland, and the marsh wetland, were reduced compared to the respective initial areas, and the upper limits of three functional regions, except for the fish pond, were increased substantially by $100.00 \%, 860.00 \%$, and $700.00 \%$, respectively. In Aobaotupao, the reed wetland had the largest restoration area, with a value of $(0.48,1.58) \times 10^{4} \mathrm{hm}^{2}$, which accounted for an increase of $(1500.00 \%, 2538.46 \%)$ compared to the initial area. The lower limit of the fish pond area remained unchanged compared to the original scheme, while the lower limit of the crab pond and marsh wetland areas was reduced; whereas, the upper limits of all three functional areas were increased significantly by $100.00 \%, 479.64 \%$, and $710.67 \%$, respectively. Overall, the marsh wetlands that present the highest ecological service value were observed to have a decrease in the lower limit of their area in all ecosystem types, with the exception of the Boluo Lake region, which was mainly because soak pond water and reed wetland water were prioritized for the ecological water replenishment to achieve the best restoration of the ecological functions. In comparison to the original scheme, the overall functional area optimized using the ITSP method was greatly increased, indicating that the ecological water replenishment was effective in restoring the wetland area. 
Table 3. The functional area of each land type in the different study areas within the Boluo Lake.

\begin{tabular}{|c|c|c|c|c|}
\hline \multirow[b]{2}{*}{ Name of Lake Bubble } & \multirow[b]{2}{*}{ Functional Area } & \multicolumn{3}{|c|}{ Area of Functional Areas $\left(10^{4} \mathrm{hm}^{2}\right)$} \\
\hline & & Original Scheme & $\begin{array}{l}\text { The Recommended } \\
\text { Scheme for Project }\end{array}$ & ITSP Model \\
\hline \multirow{5}{*}{ Toudaogang Reservoir } & Fish pond & $(0.03,0.05)$ & 0.40 & $(0.72,1.04)$ \\
\hline & Crab pond & $(0.00,0.00)$ & 0.00 & $(0.00,0.68)$ \\
\hline & Reed wetland & $(0.06,0.12)$ & 1.00 & $(0.00,0.96)$ \\
\hline & Marsh wetland & $(0.02,0.04)$ & 0.34 & $(0.00,0.33)$ \\
\hline & Fish pond & $(0.69,1.30)$ & 10.84 & $(2.94,8.00)$ \\
\hline \multirow{3}{*}{ Boluo Lake } & Crab pond & $(0.00,0.00)$ & 0.00 & $(0.00,0.00)$ \\
\hline & Reed wetland & $(0.26,0.48)$ & 4.00 & $(2.07,3.84)$ \\
\hline & Marsh wetland & $(0.13,0.24)$ & 2.00 & $(1.92,2.77)$ \\
\hline \multirow{4}{*}{ Mobopao } & Fish pond & $(0.07,0.13)$ & 0.00 & $(0.00,0.71)$ \\
\hline & Crab pond & $(0.00,0.00)$ & 1.07 & $(0.00,0.00)$ \\
\hline & Reed wetland & $(0.03,0.06)$ & 0.50 & $(0.00,0.48)$ \\
\hline & Marsh wetland & $(0.06,0.12)$ & 1.00 & $(0.00,0.96)$ \\
\hline \multirow{4}{*}{ Yuanbaowapao } & Fish pond & $(0.00,0.00)$ & 0.00 & $(0.00,0.00)$ \\
\hline & Crab pond & $(0.00,0.00)$ & 0.00 & $(0.00,1.14)$ \\
\hline & Reed wetland & $(0.01,0.01)$ & 0.10 & $(0.00,0.10)$ \\
\hline & Marsh wetland & $(0.03,0.06)$ & 0.50 & $(0.00,0.48)$ \\
\hline \multirow{4}{*}{ Aobaotupao } & Fish pond & $(0.00,0.00)$ & 0.00 & $(0.00,2.68)$ \\
\hline & Crab pond & $(0.20,0.37)$ & 3.05 & $(0.00,2.14)$ \\
\hline & Reed wetland & $(0.03,0.06)$ & 0.50 & $(0.48,1.58)$ \\
\hline & Marsh wetland & $(0.05,0.09)$ & 0.76 & $(0.00,0.73)$ \\
\hline
\end{tabular}

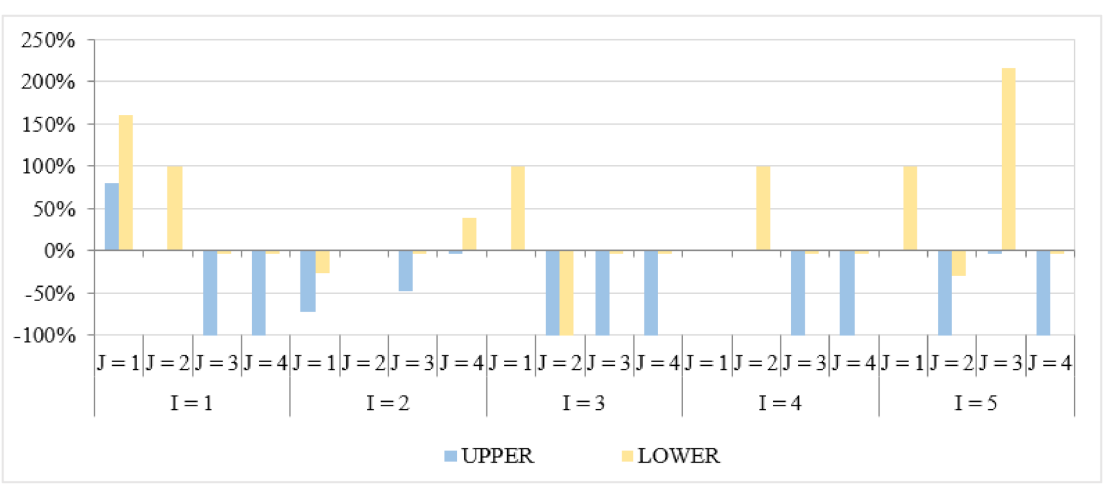

Figure 3. The extent of change in the area of the functional areas for each land type in the different study areas compared to the area in the recommended scheme for the project. ( $I=1$ to 5 represent the Toudaogang Reservoir, Boluo Lake, Mobopao, Yuanbaowapao, and Aobaotupao, respectively; J = 1 to 4 represent fish ponds, crab ponds, reed wetlands, and marsh wetlands, respectively).

Green water is mainly rainwater stored in the soil at the roots of plants, i.e., water vapour that originates from precipitation, is stored in the soil and enters the atmosphere through evaporation and transpiration; blue water is water in rivers, lakes and underground aquifers [33-35]. The Boluo Lake Wetland National Nature Reserve has a unique terrain. The reserve is located at the edge of the Songliao Sag in the southeast of the Songliao Plain. The terrain is similar to that of a basin. Owing to the unique topography of this reserve, there is poor circulation of water within the various lake bubbles in the reserve, which renders it difficult to reduce the salinity in the recharged water resources through circulation or exchange after the ecological water replenishment. As a consequence, after ecological water replenishment, the salinity in the water supply could easily interact with the groundwater and thereby affect the groundwater quality, and this salty groundwater would enter into the soil, causing soil salinization and ultimately affecting plant growth. This means that the amount of blue water is increased by ecological rehydration and that the different types of blue water circulate with each other and the salts interact. The blue 
water enters the soil and is also converted into green water to be stored by the plant roots, while at the same time the salts are absorbed by the plant roots. It is reported that reeds may effectively prevent the salinization of the land [36-38]. The salt in the water resources within the Boluo Lake Wetland National Nature Reserve could be absorbed by the reeds and removed through harvesting every year. In the optimization scheme proposed in the present report, the total amount of ecological water replenishment was reduced, thereby reducing the total salinity introduced. In addition, for the best ecological function restoration effect, the ecological water replenishment was prioritized for the water used in the pond and the reed wetland, and the area of the reed wetland was restored. As a consequence, the effectiveness of removal of water salinity through reed adsorption in the reserve was also improved.

Figure 3 depicts the change in the functional area of each land type in the different study areas compared to the area in the recommended scheme for the project. In comparison to the functional area in the recommended scheme for the project, the lower limits of the respective areas of the fish and crab pond areas in the Toudaogang Reservoir, the marsh wetlands in the Boluo Lake, the fish ponds in Mobopao, the crab ponds in Yuanbaowapao, and the fish ponds and reed wetlands in Aobaotupao were increased in the optimized simulation scheme. In addition, the lower limits of the areas of the fish ponds in the Boluo Lake, the crab ponds in Mobopao, and the crab ponds in Aobaotupao were reduced, while the lower limits of the areas of the other functional areas remained unchanged. In the optimization scheme, the upper limit of the fish pond area of the Toudaogang Reservoir was increased, the upper limit of the crab ponds area in the Toudaogang Reservoir, the crab ponds area in the Boluo Lake, the fish ponds area in Mobopao, the fish and crab ponds areas in Yuanbaowapao, and the fish ponds area in Aobaotupao remain unchanged, and the upper limit of the areas of the other functional areas was reduced. It could be observed that the restoration areas were different for the different lakes and different functional areas, and the function of the Boluo Lake Wetland National Nature Reserve had been adjusted because the model was optimized and simulated using the value of ecological services as a constraint.

\subsection{Analysis of the Change in the Ecological Service Value of the Boluo Lake Wetland Water Replenishment Project Based on the ITSP Method}

The Boluo Lake wetland water replenishment project considered the project benefits while reconstructing the wetland ecosystem and restoring its functions. The project benefits are mainly reflected in the level of restoration of the wetland area and its functions and the value of ecosystem services [39]. The value of ecosystem services refers to the benefits obtained as a result of maintaining the ecosystem functions of the earth's life support system [40]. The recommended scheme for the project regarding the value of ecological services under different indicator systems and the results of optimization using the ITSP method in the Boluo Lake Wetland National Nature Reserve are presented in Figure 4. In the present study, 15 types of ecological service functions were analyzed and the main ecological service value sequence generated was: plant adsorption $(150.07,172.88) \times 10^{6}$ $\mathrm{CNY})>$ microclimate adjustment $\left.(141.24,162.71) \times 10^{6} \mathrm{CNY}\right)>$ fish $(125.56,147.72) \times 10^{6}$ $\mathrm{CNY})>$ pollution absorption capacity $\left.(80.25,92.45) \times 10^{6} \mathrm{CNY}\right)>\operatorname{crab}(46.33,54.50) \times 10^{6}$ $\mathrm{CNY})>$ tourist development $\left.(29.69,34.21) \times 10^{6} \mathrm{CNY}\right)>$ volume of flood water mobilized $\left.(28.89,33.28) \times 10^{6} \mathrm{CNY}\right)>$ oxygen release $\left.(18.50,21.36) \times 10^{6} \mathrm{CNY}\right)>$ biodiversity maintenance $\left.(10.43,12.02) \times 10^{6} \mathrm{CNY}\right)>$ urban landscape $\left.(8.03,9.24) \times 10^{6} \mathrm{CNY}\right)>$ reed $\left.(5.47,6.32) \times 10^{6} \mathrm{CNY}\right)>$ natural landscape $\left.(3.21,3.70) \times 10^{6} \mathrm{CNY}\right)>$ scientific culture $\left.(2.01,2.31) \times 10^{6} \mathrm{CNY}\right)>$ carbon sequestration $\left.(1.90,2.19) \times 10^{6} \mathrm{CNY}\right)>$ water supply $(0.00$, $0.00) \times 10^{6} \mathrm{CNY}$ ). In this sequence, the top two indicators, namely plant adsorption, and microclimate adjustment, as well as the fourth indicator, i.e., pollution absorption capacity, are all indicators of the environmental regulation of the ecosystem, which suggests that the ecological water replenishment project in the present study focused on environmental benefits. The two indicators capable of generating direct economic value, namely fish and crab, are in the third and fifth place, respectively, indicating that the ecological water 
replenishment project in the present study does not just focus on the ecological benefits, and rather completely utilizes the local economic benefits while focusing on the ecological benefits alongside. With the exception of the three ecological service functions of fish, crab, and water supply, which remained unchanged compared to the recommended scheme for the project, the upper and lower limits of the ecological service values of the other ecological service functions were improved. In comparison to the ecological service value in the recommended scheme for the project, the largest improvement was observed in the carbon sequestration, with a value of $(23.90 \%, 21.58 \%)$, while the upper and lower limits of the ecological service value of the remaining ecological service functions were increased by over $15 \%$. This indicates that compared to the recommended scheme for the project, the ITSP method optimization scheme obtained a higher ecological service value while ensuring the restoration of the ecosystem functions.

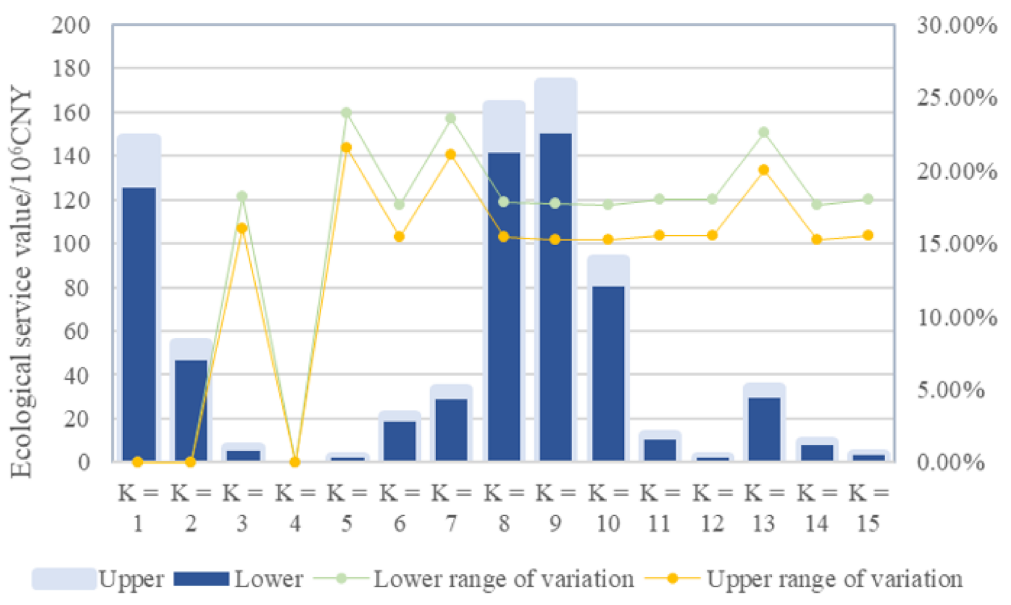

Figure 4. The value of ecological services and the magnitude of change under the different indicator systems.

4.4. Evaluation of the Feasibility of the Ecological Water Replenishment Optimization Model Based on the ITSP Method for the Boluo Lake Wetland Water Replenishment Project

The ITSP-based model constructed in the present study could be used in a wide range of applications, including the ecological water replenishment projects in different regions across the world. It is noteworthy that during the application of the constructed model, the relevant influencing factors should be adjusted according to the local characteristics, such as climate, topography, and land type of the concerned region. In addition, when applying the ITSP model, the planning area should be redefined for the size of the concerned study area, suitable scenarios should be designed, the water diversion sequence should be established according to the local water resource structure, the proportion of water supply through various modes should be adjusted according to the local water supply capacity, and the ITSP model should be customized for the actual local situation, to provide the decisionmakers with a decision plan that is most consistent with the actual local situation. For instance, when applying the ITSP model to the Momoge Reserve, which has a large area, it would be suitable to study 18 lake bubbles in the reserve and to establish three scenarios for analysis, namely a low year, a medium year, and a high water year. Moreover, when applying the ITSP model, a suitable ecological service indicator system should be selected for the assessment of the ecological service values based on the main ecological functions of the Momoge Reserve, and relevant adjustments should be incorporated in the constraints according to the actual situation of this reserve.

\section{Conclusions}

The main objective of the present study was to alleviate the water shortage situation in the lake bubble wetlands within the Boluo Lake Wetland National Nature Reserve, which was achieved by constructing an ecological water replenishment optimization model for 
the Boluo Lake Wetland replenishment project, which is based on the ITSP method and considered the minimum ecological water replenishment amount as the target. The ITSP method optimized the proposed scheme by scientifically allocating the ecological water resources and increasing the amount of flood diversion to achieve the restoration of the lake bubble wetland area and the reconstruction of the wetland ecosystem in the reserve with a minimum possible amount of ecological water replenishment. A lower ecological water replenishment implies that the amount of salt introduced due to the ecological water replenishment pathway is lower and the restoration of the reed wetland area would remove some of the salt introduced by the ecological water replenishment, thereby effectively preventing the salinization of the land in the reserve. In addition, the value of ecological services in the reserve was considered to ensure both the restoration of the ecosystem functions and the economic benefits. The ITSP method-based ecological water replenishment optimization model for the Boluo Lake wetland water replenishment project constructed in the present study may be widely applied to various ecological water replenishment projects, thereby providing the decision-makers with a feasible decision plan.

Author Contributions: Conceptualization, J.H.; methodology, L.Z.; software, J.H.; validation, J.H.; formal analysis, J.H. and L.Z.; investigation, J.H.; resources, J.H.; data curation, J.H.; writing —original draft preparation, J.H.; writing - review and editing, J.H.; visualization, J.H.; supervision, J.H.; project administration, J.H.; funding acquisition, S.S. All authors have read and agreed to the published version of the manuscript.

Funding: This research received no external funding.

Institutional Review Board Statement: Not applicable.

Informed Consent Statement: Not applicable.

Data Availability Statement: The data presented in this study is available on request from the corresponding author.

Conflicts of Interest: The authors declare no conflict of interest.

\section{References}

1. Wen, B.; Liu, X.; Li, X.; Li, Y.X. Restoration and rational use of degraded saline reed wetlands: A case study in western Songnen Plain, China. Chin. Geogr. Sci. 2012, 22, 167-177. [CrossRef]

2. Moreno-Mateos, D.; Power, M.E.; Francisco, A.C.; Yockteng, R. Structural and Functional Loss in Restored Wetland Ecosystems. PLoS Biol. 2012, 10, e1001247. [CrossRef] [PubMed]

3. Costanza, R.; Arge, R.; Groot, R.; Farber, S.; Grasso, M. The value of the world's ecosystem services and natural capital. Nature 1997, 387, 253-260. [CrossRef]

4. Woodward, R.T.; Wui, Y.S. The economic value of wetland services: A meta-analysis. Ecol. Econ. 2001, 37, 257-270. [CrossRef]

5. Mitsch, W.J.; Wang, N.M. Large-scale coastal wetland restoration on the Laurentian Great Lakes: Determining the potential for water quality improvement. Ecol. Eng. 2000, 15, 267-282. [CrossRef]

6. Shultz, S. Wetland storage to reduce flood damages in the Red River. In: Land Stewardship in the 21st Century: The Contributions of Watershed Management. Conf. Proc. 2000, 13, 363-366.

7. Wu, C.Y.; Kao, C.M.; Lin, C.E. Using a constructed wetland for non-point source pollution control and river water quality purification: A case study in Taiwan. Water Sci. Technol. 2010, 61, 2549-2555. [CrossRef]

8. Yadav, A.K.; Kumar, N.; Sreekrishnan, T.R. Removal of chromium and nickel from aqueous solution in constructed wetland: Mass balance, adsorption-desorption and FTIR study. Chem. Eng. J. 2010, 160, 122-128. [CrossRef]

9. Xie, D.; Zhou, H.J.; Ji, H.T.; An, S.Q. Ecological Restoration of Degraded Wetlands in China. J. Resour. Ecol. 2013, 4, 63-69. [CrossRef]

10. Zhang, G.X.; Wu, Y.; Wu, Y.F. A review of research on wetland ecohydrology. Adv. Water Sci. 2018, 29, 737-749. [CrossRef]

11. Yang, W. A multi-objective optimization approach to allocate environmental flows to the artificially restored wetlands of China's Yellow River Delta. Ecol. Modell. 2011, 222, 261-267. [CrossRef]

12. Wang, R.; Li, R.; Li, J.; Hu, C. A hydraulics-based analytical method for artificial water replenishment in wetlands by reservoir operation. Ecol. Eng. 2014, 62, 71-76. [CrossRef]

13. Duan, H.; Xu, M.; Cai, Y.; Wang, X.E. A Holistic Wetland Ecological Water Replenishment Scheme with Consideration of Seasonal Effect. Sustainability 2019, 11, 930. [CrossRef] 
14. Maleki, S.; Soffianian, A.R.; Solttani, S.; Pourmanafi, S. Wetland restoration prioritizing, a tool to reduce negative effects of drought; An application of multicriteria-spatial decision support system (MC-SDSS). Ecol. Eng. J. Ecotechnol. 2018, 112, 132-139. [CrossRef]

15. Xu, Y.; Wang, Y.; Li, S.; Huang, G.H. Stochastic optimization model for water allocation on a watershed scale considering wetland's ecological water requirement. Ecol. Indic. 2018, 92, 330-341. [CrossRef]

16. Yang, L.; Cong, W.; Meng, C.; Cai, B.; Liu, M. An Interval Fuzzy, Double-Sided, Chance-Constrained Stochastic Programming Model for Planning the Ecological Service Value of Interconnected River Systems. Water 2020, 12, 2649. [CrossRef]

17. Robers, P.D.; Ben-Israel, A. Interval Programming. New Approach to Linear Programming with Applications to Chemical Engineering Problems. Ind. Eng. Chem. Process Des. Dev. 1969, 8, 496-501. [CrossRef]

18. Dantzig, G.B. Linear programming under uncertainty. Manag. Sci. 1955, 1, 197-206. [CrossRef]

19. Birge, J.R.; Louverux, F.V. A multicut algorithm for two-stage stochastic linear programs. Eur. J. Oper. Res. 1988, 34, 384-392. [CrossRef]

20. Maqsood, I.; Huang, G.H. A Two-Stage Interval-Stochastic Programming Model for Waste Management under Uncertainty. J. Air Waste Manag. Assoc. 2003, 53, 540-552. [CrossRef]

21. Meng, C.; Wang, X.; Li, Y. An Optimization Model for Water Management Based on Water Resources and Environmental Carrying Capacities: A Case Study of the Yinma River Basin, Northeast China. Water 2018, 10, 565. [CrossRef]

22. Qiu, Y.; Liu, Y.; Liu, Y.; Chen, Y.; Li, Y. An Interval Two-Stage Stochastic Programming Model for Flood Resources Allocation under Ecological Benefits as a Constraint Combined with Ecological Compensation Concept. Int. J. Environ. Res. Public Health 2019, 16, 1033. [CrossRef] [PubMed]

23. Zhao, L. An Optimization Model of an Aquatic Carbon Sink: Supplementary Project at the Baltic Lake Based on Uncertain Conditions. Master's Thesis, Northeast Normal University, Changchun, China, 5 July 2020.

24. Cai, B.F. Research on the Optimization Model of Ecosystem Service Value of River-Lake Connectivity Project in Western Jilin Province. Ph.D. Thesis, Jilin University, Changchun, China, 10 June 2019.

25. Zhao, L.; Sun, S.J.; Feng, J.; Cui, P. An optimization model of an aquatic carbon sink: Supplementary project at the Baltic lake based on uncertain conditions. Renew. Energy Resour. 2020, 38, 569-577.

26. Liao, X.; Meng, C.; Cai, B.; Zhao, W. Interval-Parameter Two-Stage Stochastic Programming (IPTSP) Model of Ecological Water Replenishment Scheme in the National Nature Reserve for Improved Suitable Habitat for Rare and Endangered Migrant Birds. Water 2020, 12, 1520. [CrossRef]

27. Sodhi, M.M.S. Natural disasters, the economy and population vulnerability as a vicious cycle with exogenous hazards. J. Oper. Manag. 2016, 45, 101-113. [CrossRef]

28. Varouchakis, E.A.; Palogos, I.; Karatzas, G.P. Application of Bayesian and cost benefit risk analysis in water resources management. J. Hydrol. 2016, 534, 390-396. [CrossRef]

29. Chen, L.W.; Liu, S.X.; Wu, Y.F.; Xu, J.Y. Does Ecological Water Replenishment Help Prevent a Large Wetland from Further Deterioration? Results from the Zhalong Nature Reserve, China. Remote Sens. 2020, 12, 3449. [CrossRef]

30. Lu, S.; Sun, H.; Sun, D.; Guo, M.; Bai, X. Assessment on reservoir flood resources utilization of Ankang Reservoir, China. Resour. Polic. 2020, 68, 101745. [CrossRef]

31. Ding, Y.; Liu, H.F.; Yang, W.; Xing, L.M.; Tu, G.Q.; Ru, Z.M.; Xu, Z.H. The assessment of ecological water replenishment scheme based on the two-dimensional lattice-Boltzmann water age theory. J. Hydro-Environ. Res. 2019, 25, 25-34. [CrossRef]

32. Day, J.; Hunte, R.; Keim, R.F.; DeLaune, R.; Shaffer, G.; Evers, E.; Reed, D.; Brantley, C.; Kemp, P.; Day, J.; et al. Ecological response of forested wetlands with and without Large-Scale Mississippi River input: Implications for management. Ecol. Eng. 2012, 46, 57-67. [CrossRef]

33. Sood, A.; Prathapar, S.; Smakhtin, V. Green and Blue Water. In Key Concepts in Water Resource Management: A Review and Critical Evaluation; Lautze, J., Ed.; Routledge: London, UK, 2014; pp. 91-102.

34. Naftali, L.; Jan, V.; Jin, Y. The Root Zone: Soil Physics and Beyond. Vadose Zone J. 2018, 17, 1-6. [CrossRef]

35. Falkenmark, M.; Rockstrm, J. The New Blue and Green Water Paradigm: Breaking New Ground for Water Resources Planning and Management. J. Water Resour. Plan. Manag. 2006, 132, 129-132. [CrossRef]

36. Sánchez, J.; Fernández, J. Approach to the potential production of giant reed in surplus saline lands of Spain. Glob. Change Biol. Bioenergy 2016, 9, 1-14. [CrossRef]

37. Liu, F.; Zhang, Y.; Liang, H.; Gao, D. Long-term harvesting of reeds affects greenhouse gas emissions and microbial functional genes in alkaline wetlands. Water Res. 2019, 164, 114936. [CrossRef]

38. Douaoui, A.E.K.; Nicolas, H.; Walter, C. Detecting salinity hazards within a semiarid context by means of combining soil and remote-sensing data. Geoderma 2006, 134, 217-230. [CrossRef]

39. Li, M.N. Study on Comprehensive Utilization of Rain-Flood Resources in Western Jilin Province. Master's Thesis, Jilin University, Changchun, China, 7-11 December 2017.

40. Kreuter, U.P.; Harris, H.G.; Matlock, M.D.; Lacey, R.E. Change in ecosystem service values in the San Antonio area, Texas. Ecol. Econ. 2001, 39, 333-346. [CrossRef] 